\title{
Static and Dynamic Response of an Impeller at Varying Effects
}

\author{
Karthik Matta ${ }^{1}$, Kode Srividya $^{2}$, Inturi Prakash ${ }^{3}$ \\ ${ }^{I}$ Student (M.Tech), ${ }^{2}$ Assistant Professor Department of Mechanical Engineering, PVPSIT, Vijayawada, India \\ ${ }^{3}$ Projeect Analyst, Data Pro Office, Vizag
}

\begin{abstract}
An impeller is a rotating component of a centrifugal pump, usually made of iron, steel, bronze, brass, aluminum or plastic, which transfers energy from the motor that drives the pump to the fluid being pumped by accelerating the fluid outwards from the center of rotation. The velocity achieved by the impeller transfers into pressure when the outward movement of the fluid is confined by the pump casing. Impellers are usually short cylinders with an open inlet (called an eye) to accept incoming fluid, vanes to push the fluid radially, and a splined, keyed or threaded bore to accept a drive-shaft.The modeling of the impeller was done by using solid modeling software, CATIA V5 R18. It is proposed to design a blower with composite material, analyze its strength and deformation using FEM software. In order to evaluate the effectiveness of composites and metal blower and impeller using FEA packaged (ANSYS). Modal analysis is performed on both Aluminum and composite centrifugal blower impeller to find out first 5 natural frequencies
\end{abstract}

Keywords: CATIAV5 R18, Study of noise, Vibrations, Impeller, Aluminumand Composite, Blower, Static and Dynamic Response Using FEA.

\section{Introduction}

The impeller made out of cast material in many cases may be called rotor, also. It is cheaper to cast the radial impeller right in the support it is fitted on, which is put in motion by the gearbox from an electric motor, combustion engine or by steam driven turbine. The rotor usually names both the spindle and the impeller when they are mounted by bolts. . [1] JavadAlinejad and FarhadHosseinnejad "Aerodynamic Optimization In The Rotor Of Centrifugal Fan Using Combined Laser Doppler Anemometry And Modelling" World Applied Science Journal 17(10), 2012. The targeted topic in this particular study is the design optimization of a centrifugal fan in order to improve efficiency and rectify the non-uniformity of the flow and to eliminate the vortices that are generated by the existence of inlet distortion. Two types of rotor were used by different geometries in the current study: cylindrical and conical frustum-shaped. Numerical simulation was performed by a 3D turbulent, steady-state, incompressible flow analysis.[2] ShaliniRai, Dr.Prabha Chand "Centrifugal Fan Impeller Design With Optimization Of Blade" International Journal Of Applied Engineering Research, Vol 7, No 11, 2012. In their research redesigning a centrifugal impeller and its inlet duct were considered. The doubledischarge volute casing is a structural constraint and is maintained for its shape. To reducing the power required to operate the fan, redesign effort was geared towards meeting the design volute exit pressure.[3] O.P.Singh, Rakesh.Khilwani, T.Sreenivasulu, M.Kannan "Parametric Study Of Centrifugal Fan Performance:Experimental And Numerical Simulation" International Journal Of Advances In Engineering And Technology May 2011. In their research effect of geometric parameters of a centrifugal fan with backward- and forward-curved blades has been investigated.

Effects performed on the impeller:

1. Effect of change in blades number

2. Effect of change in blade diameter

3. Effect of change in blade angle

4. Effect of change in speeds

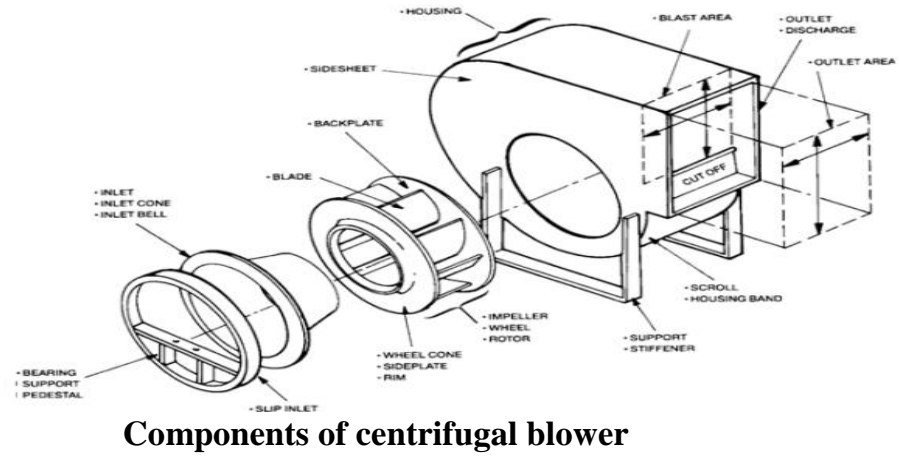




\section{Modelling By Using Catia V5 R18}

Modeling of the Blower, suction plate, supports and Impellerare done by using CATIA V5 R18. As individual parts and these are assembled as single product, saved as IGES format to import the model in to ANSYS 12.0

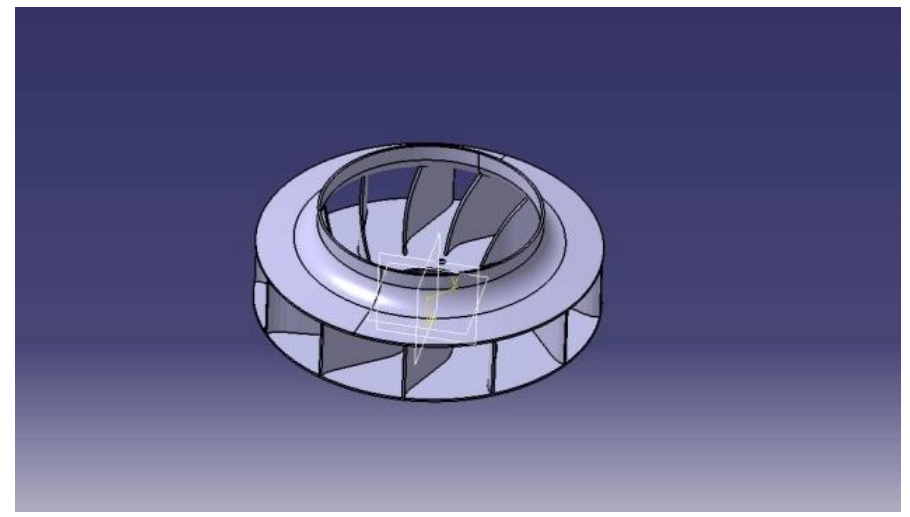

Impeller Solid Model

\section{Finite Element Analysis}

The analysis of ship Blower and Impeller has been carried out by using ANSYS 12.0 general purpose FEM software. The following analysis were done on the blower

1) Static analysis

2) Modal analysis

3) Harmonic analysis

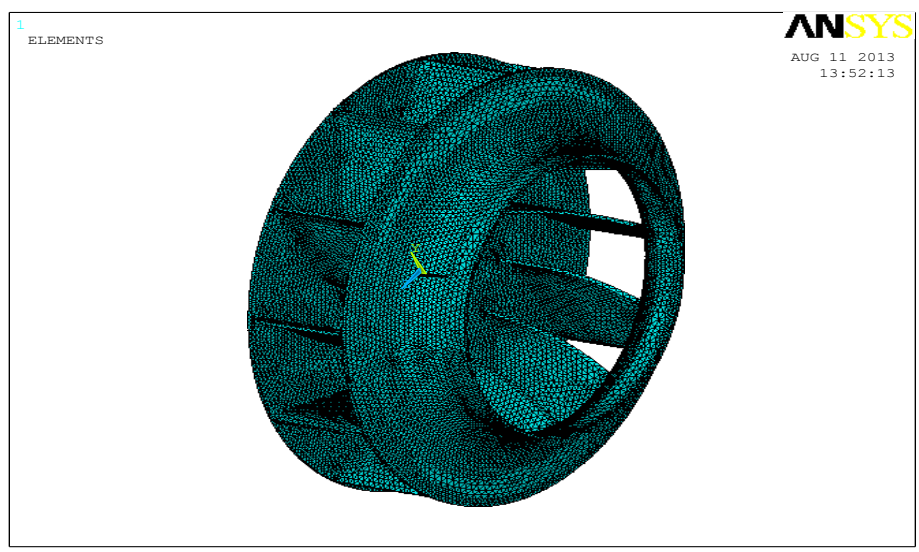

\section{Meshed Models ofImpeller}

\section{Case Description}

The complete project is aimed at examining the static and dynamic analysis of the impeller and further examining then aluminum impeller results with the composite impeller at varying effects. Also for the purpose of the total deformation and stresses developed static and dynamic analysis is done on metallic blower for present results. More over number of variations are taken for the impeller diameter, speed, blade angle and number of blades was changed for the better performance.

\subsection{INPUT DATA}

\begin{tabular}{|c|c|}
\hline Fluid & Air \\
\hline Operating speeds & $283-500 \mathrm{rpm}$ \\
\hline Pressure & $1.20 \mathrm{~kg} / \mathrm{cm}^{2}$ \\
\hline
\end{tabular}

\subsection{MATERIAL PROPERTIES OF THE IMPELLER}

The analysis is performed on

(i) Metallicimpeller and (ii) Composite impeller 
I. MATERIAL PROPERTIES OF METALLIC IMPELLER (ALUMINIUM)

Young's modulus E $=70000 \mathrm{MPa}$

Poisons ratio NUXY $=0.34$

Mass density $=2700 \mathrm{~kg} / \mathrm{m}^{3}$

Damping co-efficient $=0.006$

II. MATERIALS PROPERTIES OF COMPOSITE IMPELLER(GLASS/EPOXY)

Young's modulus $\mathrm{E}_{\mathrm{X}}=\mathrm{E}_{\mathrm{Y}}=14 \mathrm{GPa}, \mathrm{E}_{\mathrm{Z}}=8.8 \mathrm{GPa}$

Poisson's ratio NUXY $=0.13, \mathrm{NUYZ}=\mathrm{NUZX}=0.39$

Shear modulus $\mathrm{G}_{\mathrm{XY}}=4.7 \mathrm{GPa}, \mathrm{G}_{\mathrm{YZ}}=\mathrm{G}_{\mathrm{ZX}}=4.2 \mathrm{GPa}$

Mass density $=1750 \mathrm{~kg} / \mathrm{m}^{3}$

Damping co-efficient $=0.02$

Aluminum Impeller:

V. Results And Discussions

DEFORMATION MAX $=0.001407$

STRESS MAX $=58.18$

STRESS MIN $=0.1717$

MODEL ANALSYS:

\begin{tabular}{|c|c|}
\hline $\begin{array}{c}\text { MODE } \\
\text { SHAPE }\end{array}$ & FREQUENCY(Hz) \\
\hline 1 & 223.58 \\
\hline 2 & 227.26 \\
\hline 3 & 346.45 \\
\hline 4 & 885.59 \\
\hline 5 & 902.30 \\
\hline
\end{tabular}
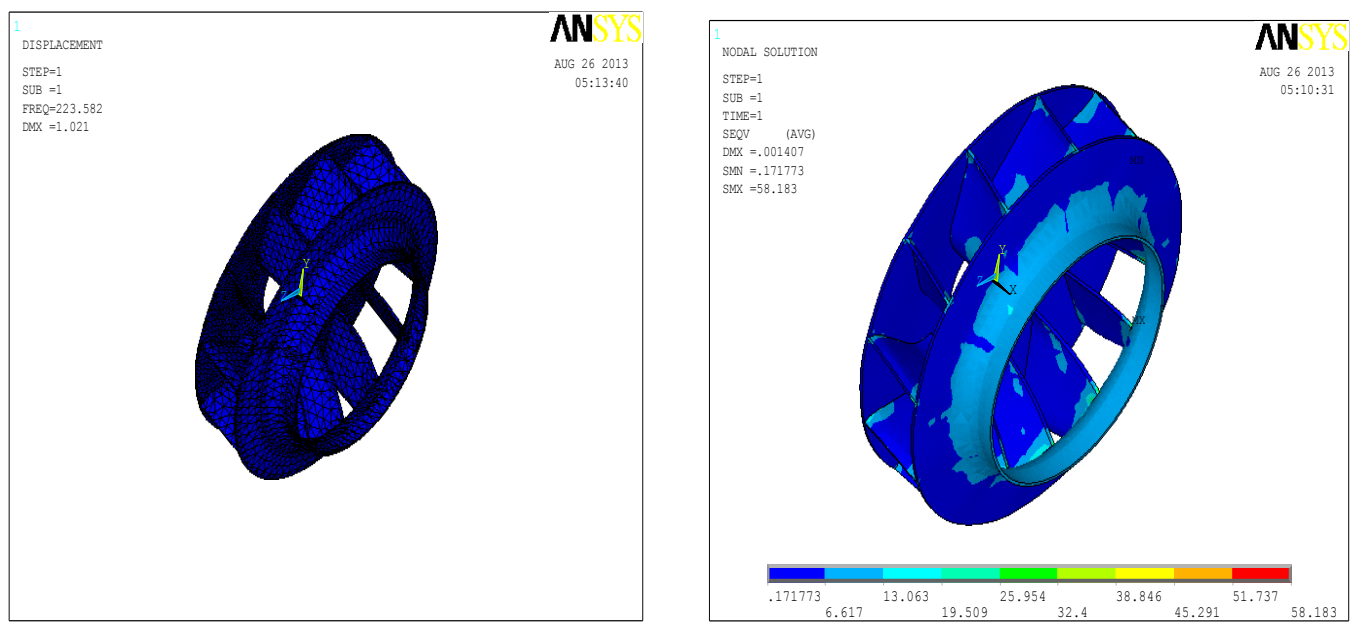

Static and dynamic analysis of aluminium impeller
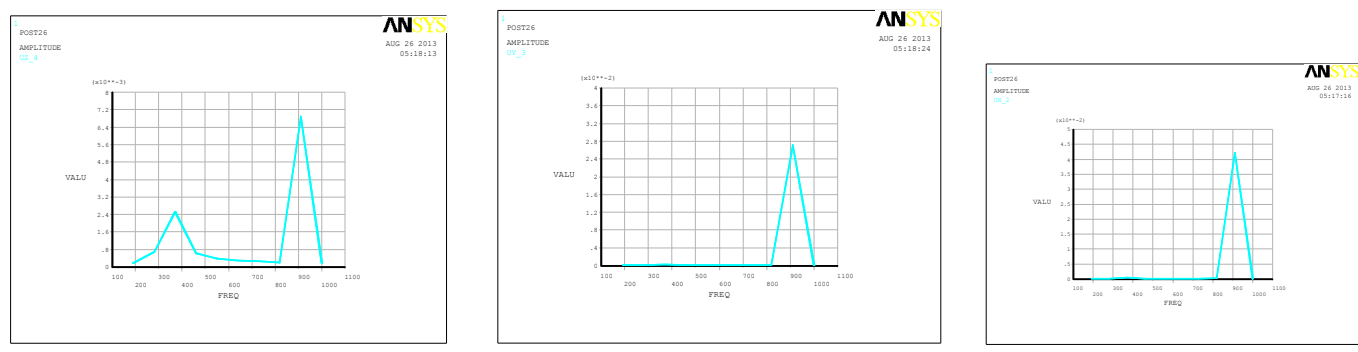

Harmonic analysis of aluminium impeller 
Composite Impeller:

DEFORMATION MAX $=0.05968$

STRESS MAX $=12.59$

STRESS MIN $=0.079$

MODEL ANALYSIS:

\begin{tabular}{|l|l|}
\hline $\begin{array}{l}\text { MODE } \\
\text { SHAPE }\end{array}$ & FREQUENCY(Hz) \\
\hline 1 & 57.05 \\
\hline 2 & 57.63 \\
\hline 3 & 67.57 \\
\hline 4 & 77.89 \\
\hline 5 & 87.67 \\
\hline
\end{tabular}

VI. Comparison Results:

6.1.1Blades variations of composite impeller: glass epoxy

\begin{tabular}{|l|l|l|l|}
\hline Number of blades & Deformation max mm & Stress $\max \left(\mathrm{N} / \mathrm{mm}^{2}\right)$ & Stress $\min \left(\mathrm{N} / \mathrm{mm}^{2}\right)$ \\
\hline 8 & 0.052 & 12.13 & 0.04 \\
\hline 10 & 0.065 & 13.10 & 0.06 \\
\hline 12 & 0.065 & 13.59 & 0.07 \\
\hline 14 & 0.065 & 13.72 & 0.08 \\
\hline 16 & 0.085 & 15.08 & 0.08 \\
\hline
\end{tabular}

6.1.2 Diameter variation of composite impeller: glass epoxy

\begin{tabular}{|l|l|l|l|}
\hline Diameter of blade & Deformation max mm & Stress $\max \left(\mathrm{N} / \mathrm{mm}^{2}\right)$ & Stress $\min \left(\mathrm{N} / \mathrm{mm}^{2}\right)$ \\
\hline 325 & 0.043 & 11.40 & 0.043 \\
\hline 350 & 0.046 & 12.07 & 0.047 \\
\hline 375 & 0.066 & 12.73 & 0.097 \\
\hline 398 & 0.069 & 12.79 & 0.099 \\
\hline
\end{tabular}

6.1.3 Blade angle variation of impeller: both aluminum and glass epoxy

\begin{tabular}{|l|l|l|l|}
\hline Blade material & Angle of blade & Deformation (max) & Stress (max) \\
\hline Aluminum & $48^{\circ}$ & 0.001407 & 58.18 \\
\hline Aluminum & $52^{\circ}$ & 0.123131 & 28.485 \\
\hline Glass epoxy & $48^{\circ}$ & 0.05968 & 12.59 \\
\hline Glass epoxy & $52^{\circ}$ & 0.03353 & 3.948 \\
\hline
\end{tabular}

6.1.4 Variation In Speed: both aluminum and glass epoxy

\begin{tabular}{|l|c|c|c|c|}
\hline Speed(rpm) & $\begin{array}{c}\text { Stress(max) } \\
\text { AL }\end{array}$ & $\begin{array}{l}\text { Stress(max) } \\
\text { COMPOSITE }\end{array}$ & Deformation(max) AL & $\begin{array}{l}\text { Deformation(max) } \\
\text { COMPOSITE }\end{array}$ \\
\hline 283 & 127.88 & 57.986 & 0.386774 & 0.45373 \\
\hline 380 & 234.07 & 103.089 & 0.601948 & 0.798462 \\
\hline 450 & 330.286 & 143.97 & 0.806327 & 1.111 \\
\hline 500 & 408.551 & 177.253 & 0.975323 & 1.365 \\
\hline
\end{tabular}



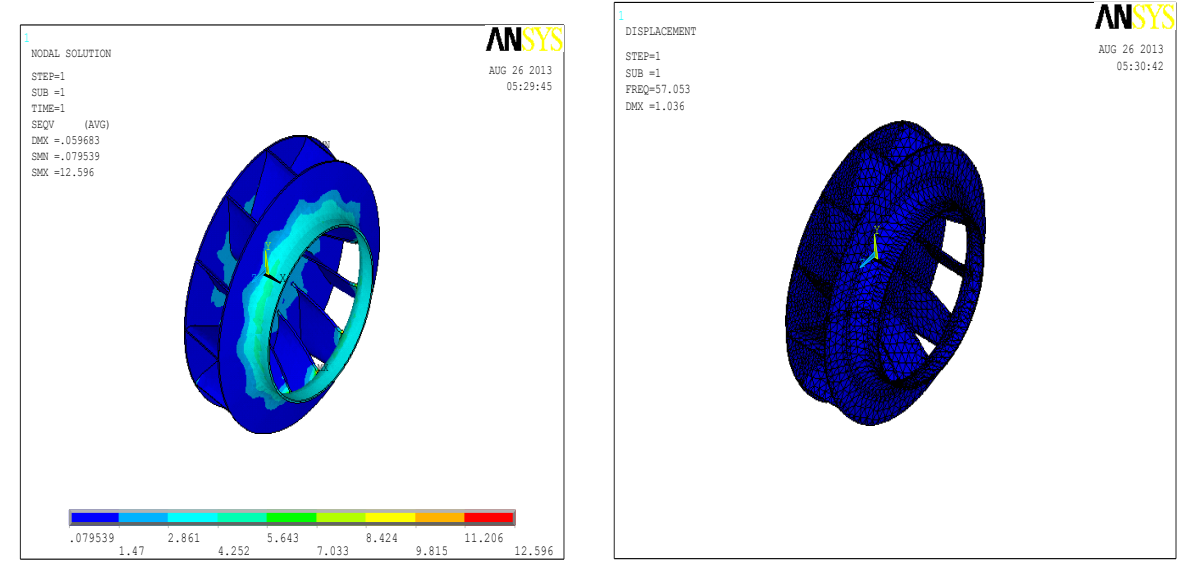

Static and dynamic analysis of composite impeller
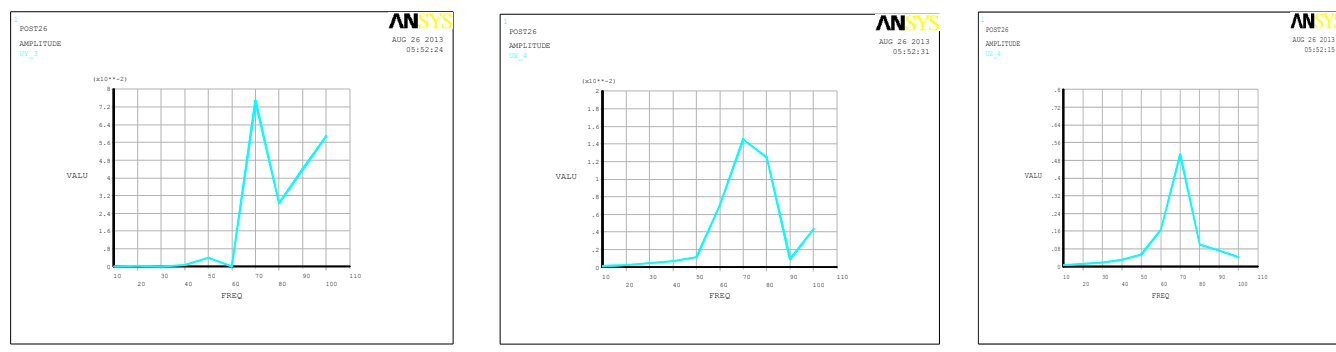

Harmonic analysis of composite impeller

\section{Conclusion}

The following conclusions are estimated from the above analysis.

1. Different types of effects are performed on the impellers with varying sizes, number of blades, varying blade angle and varying speeds. Impeller is modelled in design software CATIA V5 R18; these are used to run the analysis.

2. Three types of analysis are performed using aluminium and glass epoxy materials.

3. If number of blades, angle of the blade and outer diameter increases stresses and deformations also increases all are in allowable limit and we can increases the pressure of exhaust air. In case of varying the speeds the stresses of the composite are within the limits and are less when compared with aluminium, where the deformations are less for aluminium compared to glass epoxy.

4. Model analysis are performed to find out the natural frequencies of the impeller blade using harmonic analysis we have found that were resonance occur.

5. Total analysis results compares and found that composite materials are having less deformation and stresses.

6. All the above analysis results are in allowable limits and design is in safe conditions.

\section{Future Scope Of The Work}

1. Dynamic analysis can be performed for entire blower using composite materials.

2. We can check the lifetime of the impeller with changing various thickness of the blade FEM.

3. By changing the different lay-upsequences angles of particular composite materials we can run the analysis and find out optimum model.

\section{References}

[1]. O.P.Singh, Rakesh.Khilwani, T.Sreenivasulu, M.Kannan "Parametric Study Of Centrifugal Fan Performance:Experimental And Numerical Simulation” International Journal Of Advances In Engineering And Technology May 2011.

[2]. S.T.(Ted) Myrick Jr, W.Barry Crawford, Gerald L.Schumpert, "Changing And Controlling The First Critical Speed Of Overhung Centrifugal Fans" The Thirty-Third Turbo Machinery Symposium-2004.

[3]. N.Yagesh Sharma and k.VasudevaKaranth "Numerical Analysis Of Centrifugal Fan For Improved Performance Using Splitter Vanes" World Academy Of Science, Engineering And Technology Vol 36, 2009.

[4]. JavadAlinejad and FarhadHosseinnejad "Aerodynamic Optimization In The Rotor Of Centrifugal Fan Using Combined Laser Doppler Anemometry And Modelling” World Applied Science Journal 17(10), 2012.

[5]. Dr.Bhope and P.M.Padole "Experimental Investigation Of Stresses, Noise And Flow In Centrifugal Fan Impeller". 
[6]. YogeshR.Pathale, BeenaD.Baloni, Dr.S.A.Channiwala "Numerical Simulation Of Centrifugal Blower CFX" International Journal Of Electronics, Communication And Soft Computing Science And Engineering, International Conference On Trends In Engineering And Technology April-2012.

[7]. ShaliniRai, Dr.Prabha Chand "Centrifugal Fan Impeller Design With Optimization Of Blade" International Journal Of Applied Engineering Research, Vol 7, No 11, 2012.

[8]. Huang Chen-Kang and Hsieh Mu-En, "Performance analysis and optimized design of Backward curved airfoil centrifugal blowers", American society of Heating, Refrigerating and Air Conditioning Engineers, May 1, 2009

[9]. PrezeljJurij and Carudina Mirko, "Identification of noise sources in centrifugal blower with acoustic camera", The Journal of Acoustical Society of America, Volume 123, Number 5, p. 3824, May 2008.

[10]. J.B. Moreland, "Housing effect on centrifugal blower noise", Journal of Sound and Vibration, Volume 36, Number 2, pp. 191205,22 September 1974. 